\title{
Self-rated familiarity with autism spectrum disorders among practicing nurses: a cross- sectional study in the palestinian nursing practice
}

\author{
Ramzi Shawahna $a^{1,2}$
}

\begin{abstract}
Background: Autism spectrum disorders (ASDs) are one of the most prevalent neurodevelopmental disabilities of early childhood. Practicing nurses are in a key position to help patients with ASDs and/or their caregivers/families. This study was conducted to assess self-rated familiarity with ASDs among practicing nurses in Palestine. The study also aimed to identify the sociodemographic and practice variables that could predict high self-rated familiarity scores.

Methods: This was a cross-sectional study using a questionnaire. The study was conducted in the period between January 2019 and May 2019. The questionnaire collected: 1) the sociodemographic, pedagogic, and practice variables of the nurses, 2) their self-rated familiarity with signs and symptoms, treatment options, and community resources of ASDs, 3) their self-rated confidence in their abilities to provide counseling for parents/family/caregivers on the drugs prescribed for children/patients with ASDs and their potential adverse effects, and 4) their willingness to receive education/training on issues in ASDs.

Results: The questionnaire was completed by 357 practicing nurses. The practicing nurses self-reported inadequate familiarity with symptoms, treatment, and community resources of ASDs. The mean familiarity score was 35.8\% (SD: 18.9\%). The nurses also expressed low confidence in their ability to provide counseling services to caregivers/ families of children with ASDs. About $75 \%$ of the nurses agreed that they could benefit from taking a continuing educational/training program in the area of ASDs and about $82 \%$ of the nurses agreed that the nursing school curriculum should include courses in the area of ASDs. The multiple linear regression model showed that higher familiarity scores were predicted by having longer practical experience, having a higher academic degree in nursing, and having a continuing educational course/program on ASDs.
\end{abstract}

Correspondence: ramzi_shawahna@hotmail.com

${ }^{1}$ Department of Physiology, Pharmacology and Toxicology, Faculty of Medicine and Health Sciences, An-Najah National University, New Campus, Building: 19, Office: 1340, P.O. Box 7, Nablus, Palestine

${ }^{2}$ An-Najah Biosciences Unit, Centre for Poisons Control, Chemical and

Biological Analyses, An-Najah National University, Nablus, Palestine

(c) The Author(s). 2021 Open Access This article is licensed under a Creative Commons Attribution 4.0 International License, which permits use, sharing, adaptation, distribution and reproduction in any medium or format, as long as you give appropriate credit to the original author(s) and the source, provide a link to the Creative Commons licence, and indicate if changes were made. The images or other third party material in this article are included in the article's Creative Commons licence, unless indicated otherwise in a credit line to the material. If material is not included in the article's Creative Commons licence and your intended use is not permitted by statutory regulation or exceeds the permitted use, you will need to obtain permission directly from the copyright holder. To view a copy of this licence, visit http://creativecommons.org/licenses/by/4.0/. The Creative Commons Public Domain Dedication waiver (http://creativecommons.org/publicdomain/zero/1.0/) applies to the data made available in this article, unless otherwise stated in a credit line to the data. 
Conclusion: Findings of this study highlighted inadequate familiarity with issues of ASDs among practicing nurses. Higher familiarity was predicted by the length of practical experience, higher academic degree in nursing, and having continuing educational course/program on ASDs. Specifically designed pedagogic interventions might be helpful in increasing familiarity of practicing nurses on ASDs. More investigations are still needed to evaluate if these interventions can improve familiarity and services provided to patients with ASDs.

Keywords: Autism spectrum disorder, Familiarity, Knowledge, Nurses, Palestine

\section{Background}

Autism spectrum disorders (ASDs) are one of the most prevalent developmental disabilities of early childhood. ASDs are characterized by atypical patterns of communication and social interactions in addition to observed restricted and repetitive behavior and interest [1]. Today, ASDs are believed to be the fastest growing neurodevelopmental disabilities in the world [2, 3]. According to recent statistics, about 1 child in every 68 has been diagnosed with a type of ASDs [4]. ASDs affect individuals from all ethnicities, racial, and socioeconomic groups [4]. Due to the increasing prevalence, ASDs are considered a public health concern in many healthcare systems around the world $[5,6]$. Much of the efforts today are directed towards helping people with ASDs and their families.

Although ASDs were first reported in 1943, however, ASDs are still considered puzzling disorders because many issues in ASDs remain uncertain [7]. Therefore, it is highly likely that parents and caregivers of children with ASDs would seek advice from healthcare professionals. Healthcare professionals are expected to educate parents and caregivers on ASDs. Nurses are both respected and trusted healthcare professionals [8]. As the prevalence of ASDs is on the rise globally, nurses are expected to encounter many advice seeking parents of children with ASDs or caregivers of individuals with ASDs $[9,10]$. Nurses are expected to help caregivers/ families sort through information and resources to make better informed decisions concerning their child/patient with ASDs. To this end, nurses are expected to educate parents and caregivers on the different signs and symptoms of ASDs, drugs used to alleviate symptoms of ASDs, specific behavioral symptoms that medications seek to alleviate, the various side effects of these medications, and community resources allocated for ASDs in their regions that can be used for referral of a child/patient who is experiencing symptoms that can be linked to ASDs. Nurses should be in a key position to provide information and services to parents and/or families/caregivers on ASDs.

Palestinians receive healthcare services from three main sectors: healthcare facilities of the government, healthcare facilities of the private sector, and healthcare facilities of the United Nations Relief and Works Agency
(UNRWA) for Palestine Refugees in the Near East. Nurses are main healthcare service providers in almost all primary, secondary, and tertiary healthcare facilities of the three sectors in Palestine. Nurses also provide services to individuals in nursing homes and home care. Additionally, nurses provide services in highly specialized healthcare facilities like those providing diagnostic, behavioral, cognitive, occupational, medication, and rehabilitation therapy/management services for patients with ASDs [6]. Typically, nurses are responsible for planning and providing medical and nursing care to patients with acute and/or chronic physical and/or mental illnesses.

Assessing familiarity of healthcare professionals on a certain health issue can serve as a quality measure in modern healthcare systems. A study conducted in the state of Virginia showed that school nurses were aware of issues relevant to ASDs, symptoms associated with ASDs, and medications used in the management of ASDs [11]. Regrettably, other studies have reported many cases of healthcare professionals lacking adequate familiarity with ASDs $[9,12-17]$. A study among practicing pharmacists in Palestine reported low familiarity with ASDs [18]. More recently, knowledge gaps of issues in ASDs were also identified among Palestinian medical students [19]. It has been argued that healthcare professionals who lack adequate familiarity with ASDs are not expected to deliver optimal healthcare services and advice to families and caregivers of patients with ASDs. Because nurses are important healthcare providers in the Palestinian healthcare system, nurses are supposed to be adequately familiar with issues in ASDs in order to help caregivers/families of patients with ASDs.

To this date, practicing nurses in the Palestinian practice were not assessed for their familiarity with ASDs. Therefore, little is known on how practicing nurses in Palestine self-rate their familiarity with ASDs. Additionally, little on is known on how practicing nurses in Palestine self-rate their confidence in their abilities to provide counseling for parents/family/caregivers on the drugs prescribed for children/patients with ASDs and their potential adverse effects, willingness to receive education/training on issues in ASDs. The aims of this study were to: 1) assess self-rated familiarity of practicing nurses in Palestine with regard to ASDs, 2) assess self- 
rated confidence of practicing nurses in Palestine in their abilities to provide counseling for parents/family/ caregivers on the drugs prescribed for children/patients with ASDs and their potential adverse effects, 3) assess willingness of practicing nurses in Palestine to receive education/training on issues in ASDs, and 4) identify the sociodemographic and practice variables that could predict high self-rated familiarity scores.

\section{Methods}

\section{Design of the study}

The current investigation was a cross-sectional study in the Palestinian nursing practice. The study was conducted in the period between January 2019 and May 2019. The present study adheres to the Strengthening the Reporting of Observational Studies in Epidemiology (STROBE) Statement for reporting cross-sectional observational studies as shown in Supplementary Table S1.

\section{Study nurses and sampling}

The sample size needed for the present study was calculated using a calculator that is commonly used to compute sample sizes. The calculator can be accessed online through the link (www.raosoft.com). The calculator estimates sample sizes using Daniel's formula [20]. For this study, the number of practicing nurses needed for this study was estimated for a population of 3000 nurses practicing in the different healthcare facilities across the West Bank of Palestine. The number of nurses was estimated at a $95 \%$ confidence interval (CI) and tolerating a default margin of error of $5 \%$. For this study, 341 practicing nurses were needed. To ensure recruiting the sample size needed for this study, 400 nurses were invited to participate in this study. A total of 357 practicing nurses participated in this study, giving a high response rate of $89.3 \%$.

Participants were registered nurses who were licensed to practice nursing by the Palestinian Ministry of Health. Practicing nurses were visited and recruited in their places of work. The principal investigator contacted practicing nurses through personal contacts in the main healthcare facilities across the West Bank of Palestine. These healthcare facilities were located in the different governorates of the West Bank: Jenin, Tulkarem, Tubas, Nablus, Qalqilya, Salfit, Ramallah and Al Bireh, Jericho, Jerusalem, Bethlehem, and Hebron. The principal investigator and the key contact nurses explained the objectives of the study to the potential participants and invited them to take part in the study. Nurses were included in this study when they met the following inclusion criteria: 1) were licensed to practice nursing in Palestine by the Ministry of Health, 2) were practicing in a healthcare facility that was visited by patients with ASDs either for acute and/or chronic physical and/or mental illnesses, 3) willing to respond to items in a questionnaire, and 4) providing an informed consent. Nursing students/ trainees and those who were not have a license to practice nursing in Palestine were not recruited. Participation in this study was voluntary and the study was conducted without financial incentives.

\section{The questionnaire}

The questionnaire used in this study was based on previous studies conducted to assess familiarity of healthcare professionals of issues in ASDs [11, 13, 14, 21]. The questionnaire contained 17 items and was in three sections. The first section contained 8 items to collect the sociodemographic, pedagogic, and practice variables of the practicing nurses who participated in the study like age in years, gender, settings in which nurses were practicing, length of practical experience as a nurse, academic degree in nursing, and place of residence. Nurses were also requested to indicate whether they have taken course(s) on ASDs during their academic nursing degree program or not and whether they have taken a continuing education course/program on ASDs. The second section contained 6 items to collect self-rated familiarity with the signs and symptoms of ASDs, familiarity with the different classes of drugs used to alleviate symptoms of ASDs, familiarity with the specific behavior that could be linked with ASDs that drugs seek to alleviate, the different adverse effects caused by the drugs used to alleviate symptoms of ASDs, familiarity with how to help parents/families/caregivers sort through information to make better informed decisions about their child/patient with ASDs, and familiarity with the allocated resources within the community resources in your region that could be used for referral of a child/patient who is experiencing symptoms that can be linked to ASDs. The nurses had to self-rate the extent to which they were familiar with each item on a Likert scale of $1-5$. Scoring 1 indicated complete unfamiliarity and scoring 5 indicated complete familiarity. The third section contained 3 items to collect confidence of the nursing in their abilities to provide counseling for parents/family/caregivers on the drugs prescribed for children/patients with ASDs and their potential adverse effects, whether they disagree/ agree that they could benefit from taking a continuing educational/training program on ASDs, and whether they disagree/agree that the nursing school curricula should include courses in the area of ASDs. Again, the nurses had to express their disagreement/agreement on each item on a Likert scale of 1-5. Scoring 1 indicated strong disagreement and scoring 5 indicated strong agreement. Nurses filled the questionnaires in a privacy in their places of work. 
Piloting and reliability testing of the questionnaire Copies of the questionnaire were distributed to 30 nurses who did not participate in the full study. The nurses were asked to rate the questionnaire for readability, clarity, and compressibility. Some sentences were rephrased to improve readability and comprehensibility. To assess the stability of the scores over a short time period, the test-retest reliability was used. Nurses were requested to complete the questionnaire and after a short period of time $(30 \mathrm{~min}-2 \mathrm{~h})$, the nurses were requested to complete the questionnaire again. The matching scores in both rounds were compared using Pearson's correlation. Acceptable stability was ensured by a Pearson's correlation coefficient $(r)$ of $>0.80$. The internal consistency (relatedness of the items) was tested using Cronbach's $\alpha$ statistics. Internally consistent tools should have $0.70 \leq \alpha \leq 0.95$ [22]. The Pearson's $r$ was 0.93 (95\% CI =0.90-0.95) with a $p<0.001$ which indicated an excellent stability of scores over a short period of time. The Cronbach's $\alpha$ was 0.79 which indicated good internal consistency of the items used in the study tool.

\section{Statistical analysis}

Familiarity scores were transformed into percentages as follows: 1 was transformed to $0 \%, 2$ was transformed to $25 \%$, 3 was transformed to $50 \%$, 4 was transformed to $75 \%$ and 5 was transformed to $100 \%$. The possible raw familiarity scores could range from 6 to 30 and the possible transformed percentages could range from 0 to $100 \%$. The data were entered into and statistical analyses were conducted using IBM SPSS for Windows, version 21.0 (IBM). Because the sample size was more than 300, absolute skewness and kurtosis values were used to determine whether the data followed normal distribution or not [23, 24]. Absolute skewness values within the range of -2.0 and +2.0 and absolute kurtosis within the range of -7.0 and +7.0 indicate normally distributed data. In this study, the absolute skewness and absolute kurtosis values were within the range of -2.0 and +2.0 and -7.0 and +7.0 , respectively. The continuous variables like age and length of practical experience were categorized around the mean. Data were expressed as means with their corresponding standard deviation (SD). Differences between familiarity scores among nurses were assessed using Student's $t$-test. Correlations were investigated using Pearson's correlation coefficients. To control potentially confounding variables and identify predictors of higher familiarity scores, a multiple linear regression model was used. Variables with a $p$-value of $<0.1$ in the Student's $t$-test and Pearson's correlations were retaining in the model. The adjusted $R^{2}$ value with a $p$-value of $<0.05$ was used to assess the goodness-of-fit of the model. Tolerance values of $>0.1$ and variance inflation factors close to 1 indicated absence of multicollinearity issues $[25,26]$. In this study, $p$-values of $\leq 0.05$ were considered statistically significant.

\section{Ethics approval and consent to participate}

All procedures performed involving human participants were in accordance with the ethical standards of the institutional and national guidelines. The procedures were also consistent with the ethical principles specified in 1964 Declaration of Helsinki and its later amendments. Studies that are associated with no/minimal risk to the study participants are "Exempt" from review by Institutional Review Boards/ Ethics Committees. This study assessed self-rated familiarity with ASDs among nurses and involved no/ minimal risk to the study participants. The Institutional Review Board (IRB) of An-Najah National University approved this exemption and the protocol of this study. The study participants provided written informed consent before they took part in the study. Before analysis, data were entered into spreadsheets anonymously.

\section{Results}

Sociodemographic, pedagogic, and practice variables of the practicing nurses

In this study, the mean age of the nurses was 29.2 years (SD: 7.0) and the mean length of practical experience as a nurse was 7.6 years (SD: 6.9). Of the nurses, more than half $(57.4 \%)$ were younger than 29 years old and more than $60 \%$ were females. The vast majority (about 97\%) were nurses practicing in a hospital setting. Of the nurses, $42 \%$ were in practice for 7 or more years. The majority (about $84 \%$ ) had a Bachelor of Science degree in nursing. About $32 \%$ of the study participants lived in urban areas. About $55 \%$ of the nurses had course(s) on ASDs during their academic nursing degree program and only about $18 \%$ had a continuing educational course/program on ASDs. The sociodemographic, pedagogic, and practice variables of the study nurses are shown in Table 1.

\section{Familiarity of the practicing nurses with signs and symptoms, treatment options, and community resources of ASDs}

Nurses expressed the extent of their self-reported familiarity with signs and symptoms, treatment options, and community resources of ASDs. The mean familiarity score was $35.8 \%$ (SD: $18.9 \%$ ). The distribution of the responses of the practicing nurses on each familiarity item is shown in Table 2 .

Nurses were relatively modest in expressing their self-reported familiarity with signs and symptoms, treatment options, and community resources of ASDs. 
Table 1 Sociodemographic, pedagogic, and practice variables of the study nurses $(n=357)$

\begin{tabular}{|c|c|c|}
\hline Variable & $\mathrm{n}$ & $\%$ \\
\hline \multicolumn{3}{|l|}{ Age (years) } \\
\hline$<29$ & 205 & 57.4 \\
\hline$\geq 29$ & 152 & 42.6 \\
\hline \multicolumn{3}{|l|}{ Gender } \\
\hline Male & 141 & 39.5 \\
\hline Female & 216 & 60.5 \\
\hline \multicolumn{3}{|l|}{ Practice setting } \\
\hline Hospital & 346 & 96.9 \\
\hline Others (nursing homes, home care, etc) & 11 & 3.1 \\
\hline \multicolumn{3}{|l|}{ Length of practical experience as a nurse (years) } \\
\hline$<7$ & 207 & 58.0 \\
\hline$\geq 7$ & 150 & 42.0 \\
\hline \multicolumn{3}{|l|}{ Academic degree in nursing } \\
\hline Bachelor of Science degree in nursing & 298 & 83.5 \\
\hline Master of Science or other postgraduate degree in nursing & 59 & 16.5 \\
\hline \multicolumn{3}{|l|}{ Place of residence } \\
\hline Countryside & 242 & 67.8 \\
\hline Urban area & 115 & 32.2 \\
\hline \multicolumn{3}{|l|}{ Had course(s) on ASDs during the nursing degree program } \\
\hline No & 162 & 45.4 \\
\hline Yes & 195 & 54.6 \\
\hline \multicolumn{3}{|l|}{ Had continuing educational course/program on ASDs } \\
\hline No & 293 & 82.1 \\
\hline Yes & 64 & 17.9 \\
\hline
\end{tabular}

Only $10.4 \%$ of the nurses reported familiarity with how to help parents/families/caregivers sort through information to make better informed decisions about their child/patient with ASDs (item \# 5) and 12.6\% reported familiarity with community resources in their region that can be used for referral of a child/patient who is experiencing symptoms that can be linked to ASDs (item \# 6). Again, only $11.8 \%$ of the nurses reported familiarity with the different classes of drugs that were used for the treatment of the different symptoms of ASDs (item \# 2) and 15.1\% reported familiarity with the different sings and symptoms of ASDs (item \# 1). Of the nurses, $20.1 \%$ reported familiarity with the different adverse effects produced by the drugs used to alleviate symptoms of ASDs (item \# 4) and $21.6 \%$ reported familiarity with the specific behavior associated with ASDs that drugs seek to alleviate (item \# 3).

\section{Differences in familiarity scores among the nurses}

Table 3 shows differences in familiarity scores among the nurses with regard to their sociodemographic, pedagogic, and practice variables. Student's $t$-test and Pearson's correlations showed that nurses who were older than 29 years, had 7 or more years of practical experience, had higher degree in nursing, and have had continuing educational course/program on ASDs had significantly higher familiarity scores compared to those who were younger than 29 years, had less than 7 years of practical experience, had a basic degree in nursing, and did not have continuing educational course/program on ASDs (Table 3).

Table 2 Familiarity of nurses with symptoms, treatment, and community resources of ASDs

\begin{tabular}{|c|c|c|c|c|c|c|c|c|c|c|c|}
\hline \multirow[b]{2}{*}{$\#$} & \multirow[b]{2}{*}{ Item } & \multicolumn{2}{|c|}{$\begin{array}{l}\text { Not } \\
\text { familiar } \\
\text { at all }\end{array}$} & \multicolumn{2}{|c|}{$\begin{array}{l}\text { Not } \\
\text { familiar }\end{array}$} & \multicolumn{2}{|c|}{ Indecisive } & \multicolumn{2}{|c|}{ Familiar } & \multicolumn{2}{|c|}{$\begin{array}{l}\text { Completely } \\
\text { familiar }\end{array}$} \\
\hline & & $\mathrm{n}$ & $\%$ & $\mathbf{n}$ & $\%$ & $\mathbf{n}$ & $\%$ & $\mathrm{n}$ & $\%$ & $\mathrm{n}$ & $\%$ \\
\hline 1 & How would you rate your familiarity with the different signs and symptoms of ASDs? & 47 & 13.2 & 149 & 41.7 & 107 & 30.0 & 45 & 12.6 & 9 & 2.5 \\
\hline 2 & $\begin{array}{l}\text { How would you rate your familiarity with the different classes of drugs (e.g., antipsychotic agents, } \\
\text { antidepressant agents, central nervous system stimulants) that are used to alleviate symptoms of ASDs? }\end{array}$ & 99 & 27.7 & 134 & 37.5 & 82 & 23.0 & 32 & 9.0 & 10 & 2.8 \\
\hline 3 & $\begin{array}{l}\text { How would you rate your familiarity with the specific behavior that could be linked with ASDs that } \\
\text { drugs seek to alleviate (e.g., tendency to self-injury, hyperactivity, and obsessive-compulsive disorder)? }\end{array}$ & 61 & 17.1 & 98 & 27.5 & 121 & 33.9 & 46 & 12.9 & 31 & 8.7 \\
\hline 4 & $\begin{array}{l}\text { How would you rate your familiarity with the different adverse effects caused by the drugs used to } \\
\text { alleviate symptoms of ASDs (e.g., extrapyramidal symptoms, irritability, and sedation)? }\end{array}$ & 70 & 19.6 & 123 & 34.5 & 92 & 25.8 & 53 & 14.8 & 19 & 5.3 \\
\hline 5 & $\begin{array}{l}\text { How would you rate your familiarity with how to help parents/families/caregivers sort through } \\
\text { information to make better informed decisions about their child/patient with ASDs? }\end{array}$ & 49 & 13.7 & 149 & 41.7 & 122 & 34.2 & 31 & 8.7 & 6 & 1.7 \\
\hline 6 & $\begin{array}{l}\text { How would you rate your familiarity with the allocated resources within the community resources in } \\
\text { your region that could be used for referral of a child/patient who is experiencing symptoms that can be } \\
\text { linked to ASDs? }\end{array}$ & 103 & 28.9 & 124 & 34.7 & 85 & 23.8 & 28 & 7.8 & 17 & 4.8 \\
\hline
\end{tabular}


Table 3 Differences in familiarity scores among the nurses

\begin{tabular}{|c|c|c|c|c|c|c|c|}
\hline \multirow[b]{2}{*}{ Variable } & \multirow[b]{2}{*}{$\mathbf{n}$} & \multirow[b]{2}{*}{$\%$} & \multicolumn{2}{|c|}{ Familiarity score (\%) } & \multirow[b]{2}{*}{$p$-value } & \multirow[b]{2}{*}{ Pearson's $r$} & \multirow[b]{2}{*}{$p$-value } \\
\hline & & & Mean & SD & & & \\
\hline \multicolumn{8}{|l|}{ Age (years) } \\
\hline$<29$ & 205 & 57.4 & 33.4 & 17.1 & 0.042 & 0.11 & 0.042 \\
\hline$\geq 29$ & 152 & 42.6 & 37.6 & 20.0 & & & \\
\hline \multicolumn{8}{|l|}{ Gender } \\
\hline Male & 141 & 39.5 & 37.7 & 18.1 & 0.120 & -0.08 & 0.120 \\
\hline Female & 216 & 60.5 & 34.5 & 19.4 & & & \\
\hline \multicolumn{8}{|l|}{ Practice setting } \\
\hline Hospital & 346 & 96.9 & 36.0 & 18.9 & 0.212 & -0.07 & 0.212 \\
\hline Others (nursing homes, home care, etc) & 11 & 3.1 & 28.8 & 18.3 & & & \\
\hline \multicolumn{8}{|l|}{ Length of practical experience as a nurse (years) } \\
\hline$<7$ & 207 & 58.0 & 32.6 & 17.5 & 0.006 & 0.15 & 0.006 \\
\hline$\geq 7$ & 150 & 42.0 & 38.2 & 19.6 & & & \\
\hline \multicolumn{8}{|l|}{ Academic degree in nursing } \\
\hline Bachelor of Science degree in nursing & 298 & 83.5 & 34.6 & 18.4 & 0.007 & 0.14 & 0.007 \\
\hline Master of Science or other postgraduate degree in nursing & 59 & 16.5 & 41.9 & 20.4 & & & \\
\hline \multicolumn{8}{|l|}{ Place of residence } \\
\hline Countryside & 242 & 67.8 & 35.3 & 19.8 & 0.475 & 0.04 & 0.475 \\
\hline Urban area & 115 & 32.2 & 36.8 & 17.0 & & & \\
\hline \multicolumn{8}{|l|}{ Had course(s) on ASDs during nursing degree program } \\
\hline No & 162 & 45.4 & 33.8 & 20.4 & 0.064 & 0.10 & 0.064 \\
\hline Yes & 195 & 54.6 & 37.5 & 17.5 & & & \\
\hline \multicolumn{8}{|l|}{ Had continuing educational course/program on ASDs } \\
\hline No & 293 & 82.1 & 33.9 & 18.8 & 0.000 & 0.21 & $<0.001$ \\
\hline Yes & 64 & 17.9 & 44.5 & 17.2 & & & \\
\hline
\end{tabular}

ASDs Autism spectrum disorders, SD Standard deviation

The multiple linear regression model showed that higher familiarity scores were predicted by having longer practical experience, having a higher academic degree in nursing, and having a continuing educational course/ program on ASDs (Table 4).

\section{Training and confidence of nurses in management of} ASDs

Table 5 shows the extend of agreement of the study nurses on 3 statements on their confidence in counseling parents on ASDs and training they need to increase their familiarity with ASDs.

Only $9 \%$ of the study participants reported that they feel confident in their ability to counsel parents/family/ caregivers about the drugs and their adverse effects of prescriptions being used for the treatment of their child/ patient with ASDs (Table 5). Interestingly, about $75 \%$ of the nurses agreed that they could benefit from taking a continuing educational/training program in the area of ASDs. About $82 \%$ of the nurses agreed that the nursing

Table 4 Multiple linear regression between sociodemographic and practice variables of the nurses with familiarity scores.

\begin{tabular}{|c|c|c|c|c|c|}
\hline Variable & Unstandardized Coefficients & SE & Standardized Coefficients & $\mathbf{t}$ & $p$-value \\
\hline Age & 3.07 & 3.87 & 0.08 & 0.79 & 0.428 \\
\hline Length of practical experience as a nurse & 7.79 & 3.95 & 0.20 & 1.97 & 0.050 \\
\hline Degree in nursing & 8.41 & 2.64 & 0.17 & 3.19 & 0.002 \\
\hline Had course(s) on autism during nursing degree program & 1.99 & 1.97 & 0.05 & 1.01 & 0.313 \\
\hline Had continuing educational course/program on ASDs & 8.66 & 2.60 & 0.18 & 3.33 & 0.001 \\
\hline
\end{tabular}

ASDs Autism spectrum disorders, SE Standard error, $t \mathrm{t}$-statistics 
Table 5 Training and confidence of nurses in management of ASDs

\begin{tabular}{|c|c|c|c|c|c|c|c|c|c|c|c|}
\hline \multirow[b]{2}{*}{$\#$} & \multirow[b]{2}{*}{ Item } & \multicolumn{2}{|c|}{$\begin{array}{l}\text { Strongly } \\
\text { disagree }\end{array}$} & \multicolumn{2}{|c|}{ Disagree } & \multicolumn{2}{|c|}{ Neutral } & \multicolumn{2}{|c|}{ Agree } & \multicolumn{2}{|c|}{$\begin{array}{l}\text { Strongly } \\
\text { agree }\end{array}$} \\
\hline & & $\mathrm{n}$ & $\%$ & $\mathbf{n}$ & $\%$ & $\mathrm{n}$ & $\%$ & $\mathbf{n}$ & $\%$ & $\mathbf{n}$ & $\%$ \\
\hline 1 & $\begin{array}{l}\text { I am confident in my abilities to provide counseling for parents/family/caregivers on the } \\
\text { drugs prescribed for children/patients with ASDs and their potential adverse effects }\end{array}$ & 100 & 28.0 & 127 & 35.6 & 98 & 27.5 & 17 & 4.8 & 15 & 4.2 \\
\hline 2 & I could benefit from taking a continuing educational/training program on ASDs & 11 & 3.1 & 13 & 3.6 & 66 & 18.5 & 124 & 34.7 & 143 & 40.1 \\
\hline 3 & The nursing school curricula should include courses in the area of ASDs & 10 & 2.8 & 8 & 2.2 & 48 & 13.4 & 78 & 21.8 & 213 & 59.7 \\
\hline
\end{tabular}

school curriculum should include courses in the area of ASDs.

There was a moderate positive correlation between familiarity scores and confidence in the abilities of the nurses to provide counseling for parents/family/caregivers on the drugs prescribed for children/patients with ASDs and their potential adverse effects (Pearson's $r=$ 0.45 , p-value $<0.001$ ). Similarly, there was a moderate positive correlation between agreement of nurses on benefiting from taking a continuing educational/training program on ASDs and agreement that the nursing school curricula should include courses in the area of ASDs (Pearson's $r=0.53, p$-value $<0.001$ ).

\section{Discussion}

The present study investigated self-rated familiarity of practicing nurses of issues related to ASDs. The study also assessed self-rated confidence of nurses in their abilities to provide counseling for parents/family/caregivers on the drugs prescribed for children/patients with ASDs and their potential adverse effects, assessed willingness of nurses to receive education/training on issues in ASDs, and identified the sociodemographic and practice variables that could predict high self-rated familiarity scores.

The comparatively low familiarity scores reported in this study reflected deficits in familiarity of issues in ASDs among practicing nurses in Palestine. Deficits in familiarity of issues in ASDs were previously reported among healthcare professionals including nurses in the Middle East as well as other low- and middle-income countries like Saudi Arabia, Palestine, Egypt, Turkey, and Nigeria $[15,16,18,27-29]$. In this study, the majority of the practicing nurses reported inadequate familiarity with signs and symptoms, treatment options, and community resources of ASDs. Findings of this study were consistent with those previously reported among practicing pharmacists and medical students in Palestine $[18,19]$. In the state of Virginia, a considerable percentage of the surveyed nurses reported inadequate familiarity with the medications used for ASDs [11]. In another study that surveyed nursing faculty reported that nearly $75 \%$ of the participants had inadequate familiarity of the drugs used to manage symptoms of ASDs [12]. In the state of Mississippi, practicing pharmacists and pharmacy students also self-reported low familiarity with medications used in the management of ASDs [13, 14]. Apparently nurses in this study self-report higher familiarity with medications used to treat ASDs compared to pharmacists and pharmacy students. This could be explained by the high involvement of nurses in administering medications to patients in all healthcare systems. Compared to other healthcare professionals in Palestine, nurses often provide the largest volume of services including administration of medications to patients, especially in hospitalized patient settings. Therefore, nurses are highly likely to encounter and provide care to patients with ASDs.

In this study, $20.1 \%$ of the nurses self-reported adequate familiarity with the different adverse effects caused by drugs used in the management of ASDs symptoms and nearly $21.6 \%$ self-reported adequate familiarity with the specific behavior that could be linked to ASDs that the drugs see to alleviate. Currently, aripiprazole and risperidone are approved to alleviate the behavioral symptoms that could be linked to ASDs. It is noteworthy mentioning that behavioral problems in ASDs are often managed using potent psychotropic medications [30]. Buspirone was shown to be effective as adjunct therapy for the restrictive and repetitive behavior, especially when it is used in addition to behavioral interventions in young children with ASDs [31]. In a study conducted in Northern New England, use of psychotropic medications was 9-fold higher in children with ASDs compared to general population [32]. Medications used in children with ASDs can cause serious side effects. For example, psychotropics are associated with tardive dyskinesia, weight gain and sedation [33]. In many cases, nurses are the first to witness and report a side effect. Therefore, nurses should be familiarity with and knowledgeable of the side effects caused by medications used to treat children with ASDs in order to help manage these side effects [34]. Findings of this study showed that practicing nurses in Palestine self-report higher familiarity with medications different adverse effects caused by drugs used in the management of ASDs symptoms and the specific behavior that could be linked to ASDs that the drugs see to alleviate compared to Palestinian medical 
students and pharmacists [18, 19]. In Virginia, about $46 \%$ of the nurses surveyed reported familiarity with the adverse effects caused by the drugs used to alleviate symptoms of ASDs and, similarly, 46\% reported familiarity with the specific behavior that could be linked to ASDs [11]. Taken together, practicing nurses might have encountered and administered medications to more patients with ASDs compared to medical students and pharmacists [12].

Given the increasing prevalence of ASDs in different populations, it is highly likely that medications use will also increase. This will present a challenged for healthcare professionals including nurses. As nurses often interact with parents or caregivers of patients with ASDs, it is highly expected that they need to counsel parents on ASDs and the medication used to alleviate the behavioral symptoms associated with ASDs. A recent qualitative study in Egypt reported high informationseeking behavior among parents of children with ASDs [10]. This seems to be challenging in the current situations as the majority of the nurses in this study selfreported inadequate familiarity with the different signs and symptoms of ASDs. This also could be concerning as the majority of the practicing nurses self-reported inadequate familiarity with the resources allocated within the community in their regions that could be used for referral of children/patients with ASDs who are experiencing symptoms that could be linked to ASDs and a comparable percentage of the nurses self-reported some familiarity on how help parents/families/caregivers sort through information to make better informed decisions about their child/patient with ASDs. In previous studies, Palestinian medical students and practicing pharmacists in Palestine also reported inadequate familiarity with the resources that could be used for referral of children/patients with ASDs and how help parents/families/caregivers sort through information make better informed decisions about their child/patient with ASDs [18, 19]. Findings of this study were not surprising as $91 \%$ of the practicing nurses were not confident in their abilities to provide counseling to parents/families/caregivers about the drugs prescribed to children/patients with ASDs and their potential adverse. Lack of familiarity with community resources and how to help families of patients with ASDs sort through information was also reported among nurses in other low- and middle-income countries as well as high income countries like Nigeria, Turkey, and the US $[11,15,29]$. About $81 \%$ of the nurses surveyed in Virginia were minimally familiar with how to help parents/families/caregivers sort through information and only about $31 \%$ were familiar with resources allocated for ASDs within the communities in their region [11]. Many nurses in the study of Gardner and colleagues were not prepared to counsel family members of the patients with ASDs [12]. As ASDs are still puzzling disorders, parents/families/caregivers of children/patients with ASDs would rely on healthcare professionals including nurses to learn more about ASDs. Parents/families/caregivers would expect the practicing nurses to help them sort through information to make better informed decisions about their children/patients with ASDs and to refer them to resources allocated for patients with ASDs within the communities in their regions. Nurses who are not familiar with these resources would fail to do so. Therefore, nurses should assume responsibility and increase their familiarity with and knowledge of issues in ASDs.

In this study, the length of practical experience, higher academic degree in nursing, and having a continuing education program on ASDs were significantly associated with higher familiarity scores. These findings were not surprising as nurses with longer experience might have encountered more patients with ASDs. On the other hand, nurses who have had higher academic degree in nursing might have had received more didactics/ education on ASDs. Additionally, nurses who have had a specific continuing education program on ASDs might have become more aware and familiar with ASDs [16]. In many cases, continuing education programs increased knowledge in certain domains [16, 35, 36]. Griscti and Jacono reviewed the effectiveness of continuing education programs in nursing, in their review, continuing education programs were demonstrated to increase familiarity as well as initiatives to keep knowledge and skills of nurses up to date [36, 37]. Many studies have shown that when comparing self-perceived competences of nurses who attended a continuing education program and those who did not attend, there were statistically significant differences in favor of those who attended a continuing education program [36-38].

Findings of this study highlighted considerable familiarity deficits among practicing nurses with regard to ASDs. The sociodemographic, pedagogic, and practice variables that were associated with high and low familiarity were determined. Results of this study might be important for decision and policy makers who might wish to plan/design interventions to promote familiarity of nurses with issues in ASDs. It has been argued that better informed nurses might be able to provide higher quality services and care to patients with ASDs and/or their families/caregivers.

\section{Strengths and limitations}

Findings of this study might be interpreted after considering a number of strength points and limitations. First, this is the first assessment of familiarity of ASDs among practicing nurses in Palestine. Second, the questionnaire used in this study was previously used to assess 
familiarity of ASDs among practicing pharmacists and pharmacy students in Palestine and Mississippi [13, 14, 18]. Items in the questionnaire were adapted from previous questionnaires used to assess familiarity of ASDs among school nurses and speech-language pathologists $[11,21]$. In today's healthcare practice, people with ASDs receive services from different providers including nurses, general practitioners, psychotherapists, psychiatrists, behavioral therapists, occupational therapists, speech-language pathologists, and social workers [16]. The items used in previous questionnaires were adapted to the services provided by the healthcare providers to patients with ASDs $[11,13,14,16,18,21]$. In this study, the items used in the questionnaire were adapted to the roles of nurses in caring for patients with ASDs. Third, the necessary diagnostics were used to reassess the study tool for reliability and internal consistency. Fourth, the number of nurses who participated in this study was larger than the sample size that was needed for this study. Fifth, the practicing nurses who participated in this study were recruited from different healthcare centers in the West Bank of Palestine. Finally, appropriate statistical methods were used to determine what predicted higher familiarity scores among the practicing nurses.

This study has a number of limitations. First, the construct of familiarity equally weighed the 6 items used to measure this construct. Of those 6 items, 3 (50\%) were related to familiarity with classes of drugs used to alleviate symptoms of ASDs, their side effects, and the specific behaviors that the drugs seek to alleviate. This arbitrary weighing could have affected the construct of familiarity measured in this study. The other items measured familiarity with signs and symptoms of ASDs, how to help parents/families/caregivers sort through information, and familiarity with the allocated resources that could be used for referral of a child/patient with ASDs. It is noteworthy mentioning that the use of prescription and nonprescription drugs is significantly higher among patients with ASDs compared to their age-, sex-, and racematched cohorts without ASDs [39]. In clinical practice, nurses are responsible for preparing administering drugs to patients including those with ASDs. Therefore, nurses should be knowledgeable with the drugs and the specific behaviors that the drugs seek to alleviate. Moreover, nurses should be able to screen for and recognize side effects of the drugs [40]. Therefore, more arbitrary emphasis was placed on familiarity of nurses with the drugs used to manage patients with ASDs in this study. Second, familiarity in this study was self-reported. It could have been better if knowledge was investigated as additional domain in this study. Third, the study was conducted in a cross-sectional observational design. No intervention was conducted to increase familiarity of the nurses with regard to ASDs. Fourth, a nonprobability sampling technique was used to recruit the nurses in this study. Nonprobability sampling techniques are inherently biased when compared to probability sampling techniques. Over- or under-estimation of familiarity and knowledge could not be ruled out as a result of using this nonprobability sampling technique. Fifth, although the nurses were asked to specify the settings in which they practiced, nurses were not asked to specify which services/wards they served in. Collection of such information should have allowed comparing familiarity scores of nurses who practiced in psychiatry and pediatric services/wards to those of nurses who served in other services/wards. Finally, the sociodemographic, pedagogic, and practice variables of the nurses who declined to participate in this study were not collected. However, the response rate obtained in this study was relatively high. Additionally, the sample included nurses of both genders, different practice settings, geographical locations, age groups, academic degrees, and length of practicing experience. This should have minimized the possibility of lack of representation of certain subgroups of nurses in the Palestinian nursing practice.

\section{Conclusion}

In conclusion, findings of this study highlighted inadequate familiarity with issues of ASDs among practicing nurses. Nurses expressed low confidence in their ability to counsel parents of children with ASDs on how to sort information and showed little familiarity with community resources devoted to ASDs in their regions. Higher familiarity was predicted by the length of practical experience, higher academic degree in nursing, and having a continuing educational course/program on ASDs. Specifically designed pedagogic interventions might be helpful in increasing familiarity of practicing nurses on ASDs. More investigations are still needed to evaluate if these interventions can improve familiarity and services provided to patients with ASDs.

\section{Supplementary Information}

The online version contains supplementary material available at https:/doi. org/10.1186/s12912-021-00764-3.

\section{Additional file 1.}

\section{Acknowledgements}

The author would like to thank the nurses who participated in this study. The author would like also to thank the nurse educators for the insightful discussions they engaged in during the conduction and reporting of this study. An-Najah National University is acknowledged for making this study possible.

\section{Author's contributions}

RS was involved in the conception and design of the work, acquisition, analysis and interpretation of data, drafting, and final approval the manuscript. 


\section{Funding}

This study did not receive any specific funding.

\section{Availability of data and materials}

All the data relevant to this work are included within the manuscript or provided as supplementary materials. In case the datasets used and/or analyzed during the current study are needed, they are available from the corresponding author on reasonable request.

\section{Declarations}

\section{Ethics approval and consent to participate}

All procedures performed involving human participants were in accordance with the ethical standards of the institutional and national guidelines. The procedures were also consistent with the ethical principles specified in 1964 Declaration of Helsinki and its later amendments. Studies that are associated with no/minimal risk to the study participants are "Exempt" from review by Institutional Review Boards/Ethics Committees. This study assessed self-rated familiarity with ASDs among nurses and involved no/minimal risk to the study participants. The Institutional Review Board (IRB) of An-Najah National University approved this exemption and the protocol of this study. The study participants provided written informed consent before they took part in the study. Before analysis, data were entered into spreadsheets anonymously.

\section{Consent for publication}

Not applicable.

\section{Competing interests}

All authors report no competing interests.

\section{Received: 7 April 2021 Accepted: 24 November 2021}

Published online: 03 December 2021

\section{References}

1. Association AP. Diagnostic and Statistical Manual of Mental Disorders. 5th ed. Washington, DC: American Psychiatric Association; 2013.

2. Developmental Disabilities Monitoring Network Surveillance Year 2010 Principal Investigators; Centers for Disease Control and Prevention (CDC) Prevalence of autism spectrum disorder among children aged 8 years autism and developmental disabilities monitoring network, 11 sites, United States, 2010. MMWR Surveill Summ. 2014;63(2):1-21.

3. Blumberg SJ BM, Kogan M, Schieve LA, Jones JR, Lu MC. Changes in prevalence of parent-reported autism spectrum disorder in school-aged US children: 2007 to 2011-12. National Health Statistics Report 65, 2013, http:// www.cdc.gov/nchs/data/nhsr/nhsr065.pdf. Accessed 23 Nov 2016.

4. Christensen DL. Prevalence and characteristics of autism spectrum disorder among children aged 8 years - autism and developmental disabilities monitoring network, 11 sites, United States. MMWR Surveillance Summaries. 2012:2016:65

5. Rice C, Nicholas J, Baio J, Pettygrove S, Lee LC, Van Naarden BK, et al. Changes in autism spectrum disorder prevalence in 4 areas of the United States. Disabil Health J. 2010;3(3):186-201.

6. Shawahna R. Palestine and Autism. In: Volkmar FR, editor. Encyclopedia of Autism Spectrum Disorders. New York: Springer New York; 2017. p. 1-6.

7. Kanner L, Eisenberg L. Early infantile autism, 1943-1955. Psychiatric Res Rep. 1957:7:55-65.

8. Fealy GM. The good nurse': visions and values in images of the nurse. J Adv Nurs. 2004;46(6):649-56.

9. Gilliam JE, Unruh D, Haley K. The status of nurses' knowledge and beliefs about autism. Int J Nurs Stud. 1980;17(3):189-95.

10. Mansour, E. The information-seeking behaviour of Egyptian parents of children with Autism Spectrum Disorder (ASD): a descriptive study, Online Inform Rev. 2021:45(7):1189-207. https://doi.org/10.1108/OIR-11-2020-0494

11. Strunk JA. School nurses' knowledge of autism spectrum disorders. J School Nurs. 2009;25(6):445-52.

12. Gardner MR, Suplee PD, Jerome-D'Emilia B. Survey of Nursing Faculty Preparation for Teaching About Autism Spectrum Disorders. Nurse Educator. 2016;41(4):212-6.

13. Khanna R, Jariwala K. Awareness and knowledge of autism among pharmacists. Res Soc Admin Pharmacy. 2012;8(5):464-71.
14. Khanna R, Jariwala K, Holmes ER, Ramachandran S. Autism familiarity and knowledge among pharmacy students. Curr Pharm Teach Learn. 2014;6(1): $150-7$.

15. Igwe MN, Ahanotu AC, Bakare MO, Achor JU, Igwe C. Assessment of knowledge about childhood autism among paediatric and psychiatric nurses in Ebonyi state, Nigeria. Child Adolescent Psychiatry Mental Health. 2011;5(1):1.

16. Corden K, Brewer R, Cage E. A Systematic Review of Healthcare Professionals' Knowledge, Self-Efficacy and Attitudes Towards Working with Autistic People. Rev J Autism Dev Disord. 2021. https://doi.org/10.1007/s404 89-021-00263-w

17. Harrison AJ, Slane MM, Hoang L, Campbell JM. An international review of autism knowledge assessment measures. Autism. 2016;21(3):262-75.

18. Shawahna R, Fahed B, Qadri D, Sharawi L, Soroghli M, Dweik M. Awareness and Knowledge of Autism Spectrum Disorders Among Pharmacists: A Cross-Sectional Study in Palestinian Pharmacy Practice. J Autism Dev Disord. 2017:47(6):1618-27.

19. Shawahna R, Jaber M, Yahya N, Jawadeh F, Rawajbeh S. Are medical students in Palestine adequately trained to care for individuals with autism spectrum disorders? A multicenter cross-sectional study of their familiarity, knowledge, confidence, and willingness to learn. BMC Med Educ. 2021;21(1): 424.

20. Daniel W. Biostatistics: A Foundation for Analysis in the Health Sciences. 7th ed. New York: Wiley; 1999

21. Schwartz H, Drager KD. Training and knowledge in autism among speechlanguage pathologists: a survey. Language, Speech, Hearing Services Schools. 2008;39(1):66-77.

22. Tavakol M, Dennick R. Making sense of Cronbach's alpha. Int J Med Educ. 2011;2:53.

23. Kim H-Y. Statistical notes for clinical researchers: assessing normal distribution (2) using skewness and kurtosis. Restor Dent Endod. 2013;38(1): $52-4$

24. West S, Finch J, Curran P. Structural equation models with nonnormal variables: problems and remedies. In: Structural equation models Structural equation modeling Concepts, issues, and applications. Volume 19, edn. Edited by Hoyle R. Newbery Park: Sage; 1995.

25. Collinearity. The Concise Encyclopedia of Statistics. New York: Springer New York; 2008. p. 96-8.

26. Daoud J. Multicollinearity and Regression Analysis. J Physics. 2017;949: 012009

27. Hayat AA, Meny AH, Salahuddin N, Alnemary FM, Ahuja KR, Azeem MW Assessment of knowledge about childhood autism spectrum disorder among healthcare workers in Makkah- Saudi Arabia. Pak J Med Sci. 2019; 35(4):951-7.

28. Ahmed F, El Karmalawy E, Helmy E. Assessment of knowledge and attitude of technical nursing school students regarding autistic children. Egyptian Nurs J. 2020;17(2):117-25.

29. Keklik D, Nazik E. Knowledge about childhood autism among nurses in Turkey: A cross-sectional descriptive study. Perspect Psychiatr Care. 2021 57(4):1637-44

30. Mandell DS, Morales KH, Marcus SC, Stahmer AC, Doshi J, Polsky DE. Psychotropic medication use among Medicaid-enrolled children with autism spectrum disorders. Pediatrics. 2008;121(3):e441-8.

31. Chugani DC, Chugani HT, Wiznitzer M, Parikh S, Evans PA, Hansen RL, et al. Efficacy of Low-Dose Buspirone for Restricted and Repetitive Behavior in Young Children with Autism Spectrum Disorder: A Randomized Trial. J Pediatr. 2016;170(45-53):e41-4.

32. House SA, Goodman DC, Weinstein SJ, Chang CH, Wasserman JR, Morden NE. Prescription Use among Children with Autism Spectrum Disorders in Northern New England: Intensity and Small Area Variation. J Pediatr. 2016; 169:277-283 e272.

33. Matson $J$ L, Hess JA. Psychotropic drug efficacy and side effects for persons with autism spectrum disorders. Res Autism Spectrum Disord. 2011;5(1): 230-6.

34. Jordan S, Tunnicliffe C, Sykes A. Minimizing side-effects: the clinical impact of nurse-administered 'side-effect'checklists. J Adv Nurs. 2002;37(2):155-65.

35. Gillespie-Lynch K, Brooks PJ, Someki F, Obeid R, Shane-Simpson C, Kapp SK et al. Changing College Students' Conceptions of Autism: An Online Training to Increase Knowledge and Decrease Stigma. J Autism Dev Disord. 2015;45(8):2553-66. 
36. Iannuzzi D, Rissmiller P, Duty SM, Feeney S, Sullivan M, Curtin C. Addressing a Gap in Healthcare Access for Transition-Age Youth with Autism: A Pilot Educational Intervention for Family Nurse Practitioner Students. J Autism Dev Disord. 2019:49(4):1493-504.

37. Griscti $\mathrm{O}$, Jacono J. Effectiveness of continuing education programmes in nursing: literature review. J Adv Nurs. 2006;55(4):449-56.

38. Bullock LF, Libbus MK, Lewis S, Gayer D. Continuing education: improving perceived competence in school nurses. J School Nurs. 2002;18(6):360-3.

39. Vohra R, Madhavan S, Sambamoorthi U, StPeter C, Poe S, Dwibedi N, et al. Prescription Drug Use and Polypharmacy Among Medicaid-Enrolled Adults with Autism: A Retrospective Cross-Sectional Analysis. Drugs - Real World Outcomes. 2016;3(4):409-25.

40. Beauvois L, Kverno K. Challenges in Treating Children With Autism Spectrum Disorder: Implications for Psychiatric\&\#x2013;Mental Health Nurse Practitioners. J Psychosocial Nursing Mental Health Serv. 2020;58(12):7-12.

\section{Publisher's Note}

Springer Nature remains neutral with regard to jurisdictional claims in published maps and institutional affiliations.

Ready to submit your research? Choose BMC and benefit from:

- fast, convenient online submission

- thorough peer review by experienced researchers in your field

- rapid publication on acceptance

- support for research data, including large and complex data types

- gold Open Access which fosters wider collaboration and increased citations

- maximum visibility for your research: over $100 \mathrm{M}$ website views per year

At BMC, research is always in progress.

Learn more biomedcentral.com/submissions 